\title{
2015 Satter Prize
}

HEE OH received the 2015 AMS Ruth Lyttle Satter Prize in Mathematics at the 121st Annual Meeting of the AMS in San Antonio, Texas, in January 2015.

\section{Citation}

The 2015 Ruth Lyttle Satter Prize in Mathematics is awarded to Hee Oh of Yale University. Oh has made fundamental contributions to the fields of dynamics on homogeneous spaces, discrete subgroups of Lie groups, and applications to number theory. Oh's recent work, different parts jointly with A. Kontorovich, with N. Shah, with M. Lee, and with A. Mohammadi, has concentrated on the classical problem of relating Apollonian circle packings to equidistribution properties for groups acting on hyperbolic spaces. This work brings together in a beautiful way dynamics on homogeneous spaces, the geometry and topology of three-dimensional manifolds, and various subtle number-theoretic phenomena, for example the distribution of primes. The quantitative methods developed by Oh and her collaborators have found numerous applications by others.

\section{Biographical Sketch}

Hee Oh was born in 1969 and grew up in Gwang Ju, South Korea. She obtained her BSc in mathematics from Seoul National University in 1992 and received her PhD from Yale University in 1997, where her advisor was Gregory Margulis. Oh

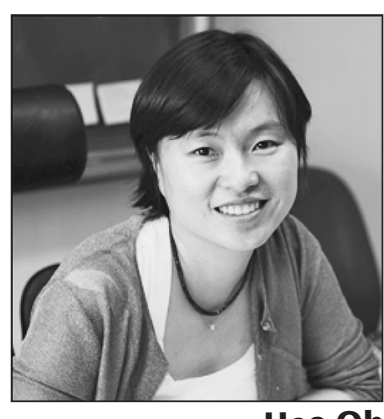
held faculty positions at Princeton University (1999-2003), the California Institute of Technology (2003-2006), and Brown University (2006-2013). Since the fall of 2013, she has been a professor of mathematics at Yale University. She has also been a KIAS scholar at Korea Institute for Advanced Study since 2008, where she visits every summer. She was an invited speaker at the International Congress of Mathematicians in 2010 and gave a joint invited address at the 2012 AMS-MAA Joint Mathematics Meeting.

DOI: http://dx.doi.org/10.1090/noti1230

\section{Response from Hee $\mathrm{Oh}$}

I am very honored to receive the 2015 Ruth Lyttle Satter Prize in Mathematics. I would like to thank my $\mathrm{PhD}$ advisor Gregory Margulis for his constant support and encouragement. I am grateful to Peter Sarnak for sharing with me his enthusiasm and inspiration, which became the source of many of my papers. In fact, it was he who introduced to me the Apollonian circle packings. Since then, I have been fascinated by the beauty of Kleinian groups, especially the dynamical aspects of Kleinian manifolds. I would like to express my gratitude to all the collaborators I have worked with, especially to Amir Mohammadi, with whom I have been exploring the theory of homogeneous dynamics on Kleinian manifolds for the last several years. His energy and friendship have been invaluable.

I am very grateful to my husband Seong-June for his support and love, and to my beautiful children, Yoony and Joy, for continuing to be proud that their mom is a mathematician despite her frequently leaving them to the care of their dad while traveling to conferences and meetings. I wouldn't be where I am now without the unimaginable support from my parents. They stayed with me for several years when my second child Joy was born in 2006, and I cannot imagine how I would have managed without their help. My sisters Hyun and Jin were always there for support, and often counseled me at difficult moments of my life.

Several years ago, my son, Yoony, challenged me to bring home the Nobel Prize when I challenged him to obtain the title of grand master in chess. When I explained to him that there is no Nobel Prize in mathematics but the Fields Medal, he then challenged me to win the Fields Medal instead. I had to excuse myself once again since my age surpassed the qualifying age limit for the medal. I am happy to report to him, now a national master, that I have received a prize of high honor.

I discovered my love of mathematics somewhat late in high school. Although I loved doing mathematics, overcoming the lack of confidence was a barrier. I share this in hopes that young women who love doing mathematics but are not confident know that they are not alone, and that being a woman does not have to hinder you from choosing the life of a mathematician. When I was a postdoctoral fellow, I happened to read an interview with Karen Uhlenbeck, who shared a similar 


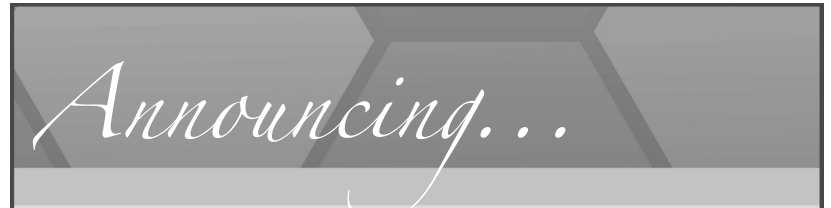

The creators of MathJobs.Org welcome you to:

\section{MathPrograms.Org}

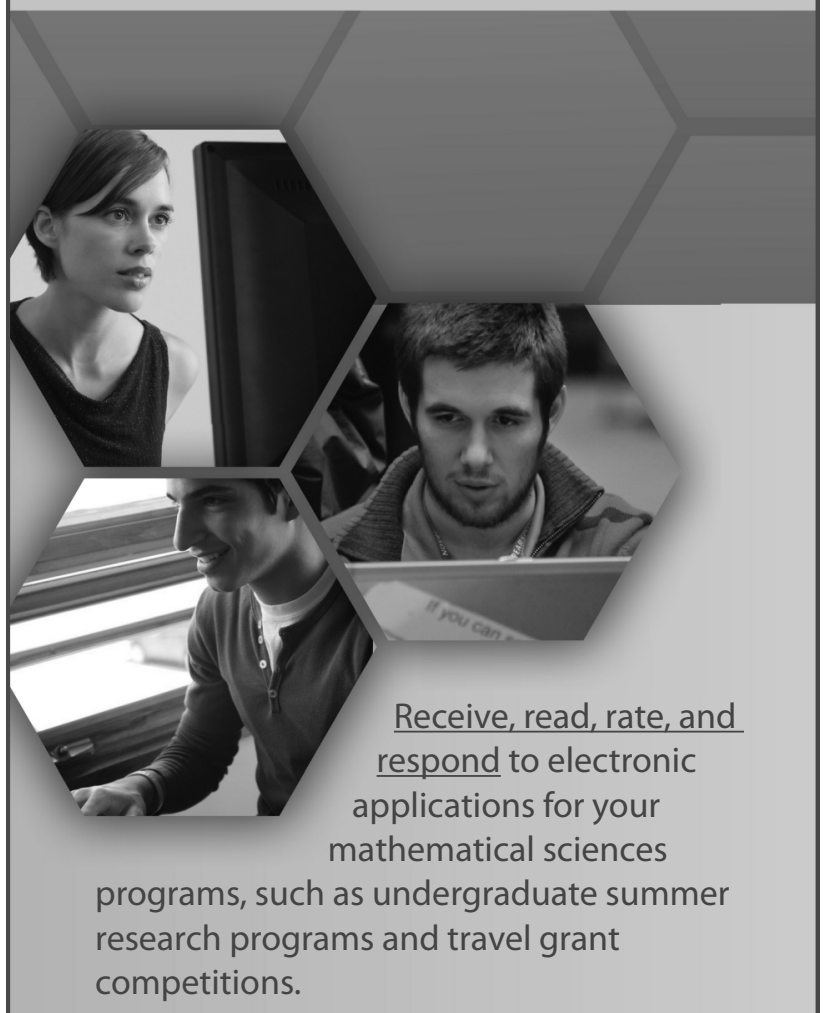

Customize your settings and control the application form; also set secure access for the admissions committee.

Enter program announcements for public display.

Download data to personal computers for use in word processing and spreadsheets or as a full permanent storage file.

\section{Service is FREE to applicants.}

\section{Institutions pay annually for} one program or for multiple programs. statement about her experience as a female mathematician. This was indeed an encouragement for me. I was lucky to have parents and teachers who have never confined me in what I could do because of my gender. I believe things are changing toward a positive direction but are still very slow. I hope this can serve as encouragement for young, bright women who wish to pursue mathematics, to have confidence in following their passion.

\section{About the Prize}

The Satter Prize is awarded every two years to recognize an outstanding contribution to mathematics research by a woman in the previous six years. Established in 1990 with funds donated by Joan S. Birman, the prize honors the memory of Birman's sister, Ruth Lyttle Satter. Satter earned a bachelor's degree in mathematics and then joined the research staff at AT\&T Bell Laboratories during World War II. After raising a family, she received $\mathrm{a} \mathrm{PhD}$ in botany at the age of forty-three from the University of Connecticut at Storrs, where she later became a faculty member. Her research on the biological clocks in plants earned her recognition in the United States and abroad. Birman requested that the prize be established to honor her sister's commitment to research and to encourage women in science. The prize carries a cash award of US\$5,000.

The Satter Prize is awarded by the AMS Council acting on the recommendation of a selection committee. For the 2015 prize, the members of the selection committee were Benson Farb, Svetlana Jitomirskaya, and Raman Parimala.

Previous recipients of the Satter Prize are: Dusa McDuff (1991), Lai-Sang Young (1993), Sun-Yung Alice Chang (1995), Ingrid Daubechies (1997), Bernadette Perrin-Riou (1999), Karen E. Smith (2001), Sijue Wu (2001), Abigail Thompson (2003), Svetlana Jitomirskaya (2005), Claire Voisin (2007), Laure Saint-Raymond (2009), Amie Wilkinson (2011), and Maryam Mirzakhani (2013). 